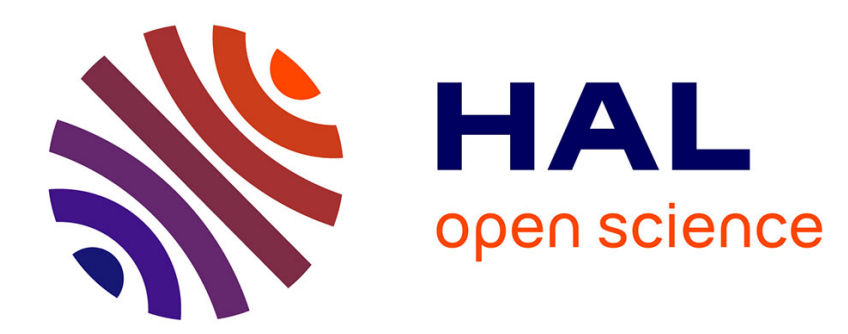

\title{
MAGNETIC PROPERTIES OF DISLOCATIONS, SPIN POLARONS
}

\author{
J. Gouyet
}

\section{To cite this version:}

J. Gouyet. MAGNETIC PROPERTIES OF DISLOCATIONS, SPIN POLARONS. Journal de Physique Colloques, 1979, 40 (C6), pp.C6-107-C6-109. 10.1051/jphyscol:1979622 . jpa-00219038

\section{HAL Id: jpa-00219038 https://hal.science/jpa-00219038}

Submitted on 1 Jan 1979

HAL is a multi-disciplinary open access archive for the deposit and dissemination of scientific research documents, whether they are published or not. The documents may come from teaching and research institutions in France or abroad, or from public or private research centers.
L'archive ouverte pluridisciplinaire HAL, est destinée au dépôt et à la diffusion de documents scientifiques de niveau recherche, publiés ou non, émanant des établissements d'enseignement et de recherche français ou étrangers, des laboratoires publics ou privés. 
MAGNETIC PROPERTIES OF DISLOCATIONS, SPIN POLARONS

\author{
J.F. Gouyet \\ Laboratoire te Physique de la Matière Condensée, Ecole Polytechnique, 91128 Palaiseau Cedex, France.
}

Résumé. - Cette note examine les caractéristiques des polarons magnétiques induits sur les dislocations du silicium par des électrons photocrées.

Abstract.- We examine in this note the characteristics of magnetic polarons induced on dislocations by photocreated electrons in silicon.

1. Introduction. - In a recent paper $/ 1 /$, exchange interaction between unpaired electrons has been estimated on the model $\mathrm{H}_{3} \mathrm{Si}-\mathrm{SiH}_{3}$. The interaction, of antiferromagnetic character, was found around $3 \mathrm{meV}$ for a distance of $3.82 \AA$ between the dangling bonds, taken precisely equal to the corresponding distance in [011] dislocations in silicon. Hence, from this information we proposed the same value for the unpaired electrons in these dislocations.

We showed that electron paramagnetic resonance experiments of Schmidt et al. /2/ could be explained without the assumption of ferromagnetic coupling.

In the absence of light, we found no large spin value on dislocations but, it is shown in this paper that photoelectrons trapped on such dislocations can induce on them magnetic polarons with large spins.

Whereas in a one dimensional Hubbard model we do not expect any information of spin polarons /3/ it is not the same case when the extra-electron is located on virtual orbitals of each silicon center possessing a dangling bond. This extra-electron is coupled to the unpaired electron on the same center by a strong exchange interaction. This interaction is ferromagnetic since Hund's rule applies. It seems that the magnetic polaron cannot explain the spin dependent recombination of photocreated electrons $/ 4,5 /$ in spite of models proposed by Lépine et al. /6/ and by R.M. White and J.F. Gouyet (unpublished).

However, the existence of a superparamegnetism on dislocations is of great physical interest.

2. Description of a spin-polaron in one dimension.-

We consider a chain of broken bonds, the orbitals of which, $\phi_{p}\left(r_{p}\right)$ are occupied, each one by an unpaired electron. This is the case for dislocations in silicon, for which it has been shown the Hamiltonian was properly represented by an Heisenberg Hamiltonian

$$
H_{0}=-2 J \sum_{p>q} \vec{s}_{p} \cdot \vec{s}_{q}
$$

As for the orbitals $\phi_{p}\left(r_{p}\right)$, they can be written in the $\mathrm{SiH}_{3}$ case /1/ :

$$
\phi_{p}=0.4(3 s)_{p}-0.2\left(2 p_{z}\right)_{p}+0.6\left(3 p_{z}\right)_{p}
$$

while the exchange interaction between two electrons on two centers $\mathrm{Si}$ in $\mathrm{SiH}_{3}-\mathrm{SiH}_{3}$ at a distance of $3.82 \AA$ is estimated around $3 \mathrm{meV}$. The corresponding $t$ and $U$ in a Hubbard Hamiltonian are found respectively equal to $3.7 \mathrm{meV}$ and $9 \mathrm{eV}$.

In this note, the anisotropy of interaction present in dislocations is neglected. The virtual states on each silicon center $q$ are described as $\psi_{q}=(4 s)_{q}$ (or $\psi_{q}=a(4 s)_{q}+b\left(4 b_{x}\right)_{q}$ if anisotropy is present) so that the excited states of the chain with one extra-electron imply linear combinations of $\psi_{q} \cdot$

Hence a photoelectron is suoposed to be trapped on a dislocation. Its exchange interaction $j$ with the unpaired electron on the same silicon center is taken positive (Hund's rule) and much larger than $|\mathrm{J}|$.

$$
j=\left\langle\phi_{p} \quad \psi_{p}|H| \psi_{p} \quad \phi_{p}\right\rangle ; \quad j>|J|
$$

but we also suppose that the ground state on a single Si center is $\left|\phi_{p} \alpha \psi_{p} \alpha\right\rangle$ and not $\left|\phi_{p} \alpha \phi_{p} \beta\right\rangle$ which is found larger by $9 \mathrm{ev}$.

The interaction between the photoelectron and the chain is written :

$$
R_{\text {int }}=-2 j \sum_{p} \vec{s}_{p} \cdot \vec{s} a_{p}{ }^{+} a_{p}
$$

where $a_{p}{ }^{+} a_{p}$ is the occupation number operator on orbital $\psi_{p}$ and $\vec{s}$ the spin operator of the supplementary electron.

Moreover :

$$
H_{1}=-t^{*} \sum_{\substack{p q \\ \text { neighbour }}} a_{p}{ }^{+} a_{q}
$$


represents the interaction between two neighbouring orbitals $\psi_{\mathrm{p}}$ and $\psi_{\mathrm{q}}\left(\mathrm{t}^{*}\right.$ is the transfer matrix element).

Approximated solutions of Il $=H_{0}+\not l_{1}+$ ll int are given in the framework of the polaron mode $1 / 7 /$.

The free energy $F_{1}$ per spin of an Heisenberg infinitc chain has been calculated by Johnson and MC Coy /8/.

In absence of magnetic field, at low temperature :

$$
F_{1}=\varepsilon_{0}-\frac{(k T)^{2}}{3|J|}+\ldots \ldots \text { with } \varepsilon_{0}=\left(-\frac{1}{2}+2 \ln 2\right) \mathrm{J}
$$

wile at high temperature

$$
F_{1}=-k T \text { in } 2-\frac{|\mathrm{J}|}{4}-\frac{3|\mathrm{~J}|^{2}}{32}+\ldots
$$

A spin polaron is then a stable of the photoelectron in the potential of $n$ parallel spins. This potential is limited at each end by two antiparaliel spins producing a potential barrier $2 \mathrm{j}$ which is probably very large.

The excitation energy of a chain with a set of $n$ parallel spins is

$-\frac{n}{2} J-n \varepsilon_{0}=-2 \ln 2 n \mathrm{~J}$

The states of the extra- electron are

$\psi_{n k}=\sqrt{\frac{2}{n}} \sum_{p=n_{0}}^{n_{0}-1+n} \sin \left[k d\left(p-n_{0}\right)\right] \cdot\left|\psi_{p}\right\rangle$

with $k=\frac{\pi v}{n d}, \nu=1,2 \ldots, n$

and their energy spectrum is :

$\varepsilon_{n k}=-2 t^{*} \cos k d$

ihe polaron energy is then, except an additive constant

$E_{p o l}^{n k}=-2 t^{*} \cos k d-2 \ln 2 n J$

Moreover, the entropy of the $n$ parallel spins is zero so that the free energy of the polaron is

$$
E_{\text {pol }}=-2 t^{*} \cos k d-2 \ln 2 n J-n F_{1}
$$

This polaron is in a stable equilibrium at $T$ when $\delta F_{\text {pol. }}=0$ that is to say

$-2 \ln 2 J-F_{1}+2 t^{*} \sin (k d) \cdot\left(\frac{-k d}{n}\right)=0$

or when $\dot{k} d<<I$, has an equilibrium length $\left(n_{p o l} x d\right)$ with

$n_{\text {pol }}=\left(\frac{2 \pi^{2} v^{2} t^{*}}{-2 \ln 2 J-F_{1}}\right)^{1 / 3}$

At low temperature $k T \ll|\omega|$ :

$$
n_{p 01} \simeq\left(\frac{2 \Pi^{2} v^{2} t^{*}}{2: 27|J|+\frac{(k T)^{2}}{3|J|}}\right)^{1 / 3}
$$

while at high temperature $k T \gg|J|$

$$
n_{\text {pol }}=\left(\frac{2-\Pi^{2} v^{2} t^{*}}{\frac{1}{4}+\ln 2(k T-2 J)}\right)^{1 / 3}
$$

The polaron spectrum is a linear function of

$\mathrm{n}_{\mathrm{pol}}$ :

$$
E_{p o l}=E_{0}-\left(3 \ln 2 J+\frac{F_{1}}{2}\right) n_{p o l}
$$

As a consequence we note that at high temperature the relative number of trapped electrons decreases as $\mathrm{T}-1 / 3$.

The figure shows the variation of $n_{p o l}$ and $E_{p o l}$ as a function of $T$ for a reasonable set of parameters. To this spectrum of stable polarons we can imagine to add all possible excitation with $k=\frac{\Pi v^{\prime}}{n(\nu) d}$, where $\nu^{\prime}=1,2 . . \nu, \ldots . . n(v)$ as well as excitations of the remaining spins on the chain.

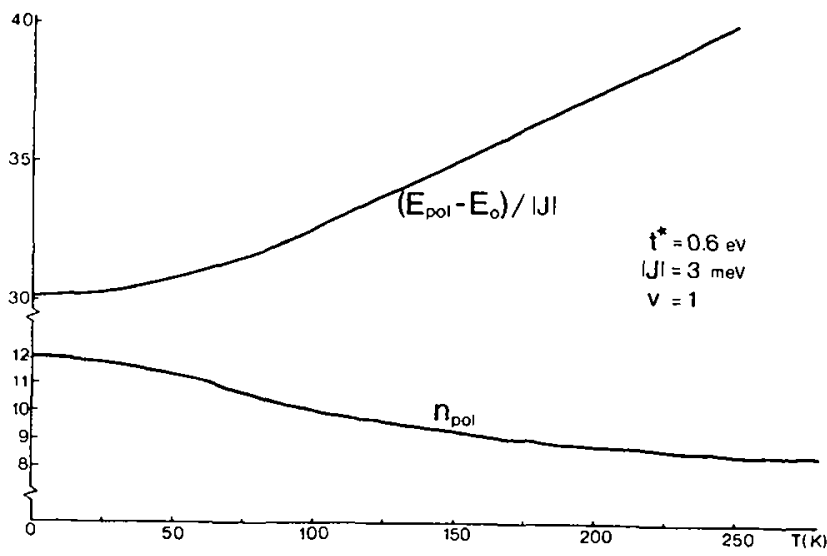

Fig. 1 : Energy and number of aligned spins of a polaron as a function of temperature for a reasonable set of parameters.

\section{Estimation of the_effective mass for for these_polarons. -}

The transfer matrix element can be simply calculated $t_{p 01}=-\frac{J}{2} \cos (k d) n_{p o l}$

giving an effective mass decreasing with the inverse of the length of the polaron.

3. Conclusion. - As the conclusion, it would be interesting to perform magnetic resonance experiment under high intensity light irradiation. The effect, both on the resonance line intensity and shape could give an experimental confirmation of this superparamagnetism. In particular, an increase in the creation rate of photoelectrons would saturate the number of polarons in each dislocation. 


\section{References}

/1/ White, R.M. and Gouyet, J.F., Phys. Rev. 16 (1977) 3596.

12/ Schmidt, U., Weber, E., Alexander, H. and Sander, W. , Solid State Commun 14 (1974) 735.

/3/ Brinkman, W.F. and Rice, T.M., Phys. Rev. B 2 (1970) 1324.

/4/ Lēpine, D., Phys. Rev. B 6 (1972) 436.

15/ Kaplan, D., Solomon, I. and Mott, N.F., J. Physsique Lett. 39 (1978) L 51.

16/ Lépine, D., Grazhulis, V. and Kaplan, D., Proceedings of the Thirteenth International Conference on the Physics of Semiconductors, Rome, 1976. See also a recent paper by L'vov, V.S., Tretyak, 0.V. and Kolomiets, I.A., Sov. Phys. Semicond. 11 (1977) 661.

/7/ Kasuya, T., Solid State Commun. 8 (1970) 1635. See also Mott, N., Metal-Insulatōr Transition. (Taylor and Francis L.T.D.) 1974, p. 86.

18/ Johnson, J.D., and McCoy, B.M., Phys. Rev. 6 (1972) 1613. 